\title{
Borges e o conto policial: uma metáfora para a criação literária
}

\author{
Borges and detective short story: a metaphor for literary \\ creation \\ Juliana QUEIROZ \\ Universidade Federal do Pará (UFPA)
}

\begin{abstract}
RESUMO: Este artigo apresenta, em um primeiro momento, um panorama do gênero policial que tem como um de seus autores primeiros o norte-americano Edgar Allan Poe e sua narrativa "Os crimes da rua Morgue" (1841). A partir desse conto e das narrativas produzidas no século XX, teóricos como Boileau, Narcejac e Tzvetan Todorov criam tipologias para o gênero, evidenciando suas principais características e diferenciando as narrativas clássicas daquelas consagradas posteriormente pelo modelo americano e francês. A segunda parte do artigo apresenta o escritor argentino Jorge Luis Borges como grande apreciador do gênero, crítico e também autor de narrativas policiais. Seu conto "A morte e a bússola" (1942) dialoga diretamente com preceitos do modelo clássico, mas também com pressupostos que ele mesmo criou no ensaio "Os labirintos policias e Chesterton" (1935). O conto "A morte e a bússola" pode também ser lido como uma metáfora para a atividade de leitura e interpretação do texto literário, temática que perpassa toda a obra borgeana.
\end{abstract}

PALAVRAS-CHAVE: Gênero policial. Jorge Luis Borges. A morte e a bússola.

ABSTRACT: First, this article intends to show a wide view of the detective story as a gender. It is well known that north-American Edgar Allan Poe is considered one of the first authors to write a detective short story: The murders in the Rue Morgue (1941). Some critics such as BoileauNarcejac and Tzvetan Todorov have classified this gender pointing out some characteristics from the first model invented by Poe. They have also distinguished different models according to the narratives published in the $20^{\text {th }}$ century. In the second part of this article, we will evidence the Argentinian writer Jorge Luis Borges as a great fancier of the gender and also as a great critic and writer of short narratives. His short story "A morte e a bússola" (1942) dialogues directly to the principles of the classic detective novel but also to some assumptions he created himself in the essay "Os labirintos policiais e Chesterton" (1935). "A morte e a bússola" can also be read as a metaphor for literary text reading and interpreting activity, a topic that runs through all Borges'work.

KEYWORDS: Detective story. Jorge Luis Borges. A morte e a bússola.

\section{Introdução}

Sabidamente, "Os crimes da rua Morgue" de Edgar Allan Poe é considerada a primeira típica narrativa policial na história literária. No entanto, diversos teóricos, ao investigarem as origens do gênero e a criação de Poe, elencam certos aspectos que remontam aos primeiros traços investigativo-dedutivos de que se têm notícia: "a raiz profunda e, por assim dizer, metafísica do romance policial está aí: somos seres 
empenhados em extrair, de qualquer jeito, o inteligível do sensível" (BOILEAU; NARCEJAC, 1991, p.10).

Ainda conforme as palavras desses autores, o mistério é aquilo que se constata, se toca (sensível) e o problema está em desvendá-lo, torná-lo inteligível. Este mesmo princípio comporia os enigmas decifrados por Édipo diante da Esfinge, bem como a fábula persa em torno dos príncipes de Sarendip. Assim, como demonstra o ensaio Le Roman Policier, de Pierre Boileau e Thomas Narcejac, a tentativa, através de um raciocínio lógico, de se clarificar uma suposta verdade obscurecida por um enigma é muito anterior a Poe. Contudo, foi o escritor americano quem primeiro deu forma à figura do detetive e aplicou à ficção uma técnica de raciocínio lógico-detetivesco.

Quais seriam estas circunstâncias? De acordo com o ensaio em questão, no início do século XIX, a ciência passou a se julgar capaz de fornecer uma explicação para tudo e, assim, o próprio homem não escapou a este princípio. Teorias como a fisiognomonia, por exemplo, que datam do século XVII vão ganhar maior destaque a partir da crença de que "não há foro íntimo e os movimentos mais secretos de nossa consciência se traduzem imediatamente em jogos de fisionomia" (BOILEAU; NARCEJAC, 1991, p.17). Tais fatores possibilitaram que o homem, como toda a matéria, fosse investigado por processos parecidos:

\footnotetext{
O cientista, transformado em detetive, não se deixará mais prender pelas aparências, mas, armado da lógica a serviço da observação, remontará dos efeitos às causas, deduzirá das causas novos efeitos e, pouco a pouco, prenderá o culpado em uma rede de provas. Ora, o que é a prova? Uma ligação, uma relação evidente. Dupin não raciocina melhor do que Édipo. O que ele possui a mais é o domínio consciente dos processos da ciência, em um terreno novo, que é o dos 'comportamentos', para retomar aqui um termo emprestado do behaviorismo. Se Édipo tivesse sido dotado do mesmo equipamento intelectual, não só teria escapado à Esfinge -, aliás, o que ele fez - mas ainda teria descoberto os motivos da Esfinge e, de algum modo, desvendado as razões profundas de seus crimes. Tê-la-ia aprisionado e obrigado a confessar. (BOILEAU; NARCEJAC, 1991, p.18)
}

Poe deu vida e consagrou um modo de narrar com uma estrutura bem específica: um crime misterioso, a(s) vítima(s), o detetive e a sua investigação. Varie-se o enfoque e teremos os diferentes tipos de romance policial. Embora tenham ocorrido mudanças nas narrativas ao longo dos séculos XIX e XX, Boileau e Narcejac não acreditam que isto represente um desenvolvimento estrutural no gênero. As molas mestras (crime+vítima, detetive, assassino) são imutáveis se se quer produzir um relato policial. No que tange à 
classificação das ficções posteriores a Poe e suas diferentes adaptações ao longo do século XX, destaca-se o ensaio de Tzevetan Todorov intitulado "Tipologia do romance policial" traduzido e publicado pela Perspectiva em 1970, texto em que o autor distingue duas variantes básicas: o romance de enigma e o romance negro. Com respeito à primeira 'espécie', denominada também de policial clássico, Todorov enumera suas características principais. O relato tem início quase sempre com a descoberta do crime, mas não há descrição da cena do assassinato propriamente dita, apenas dos vestígios deixados pelo assassino, o(s) corpo(s), ou seja, aquilo que o detetive 'vê'. A narrativa vai girar em torno da investigação e culminar na descoberta do culpado nas últimas páginas, sendo contada predominantemente por um amigo ou ajudante do detetive. O leitor acompanha o raciocínio, a lógica utilizada ao reunir as provas, sua combinação e, por último, a conclusão final e o desvendamento do mistério. O detetive é, por definição, imune a qualquer falha ou risco. Aos leitores é dada a garantia de um final claro e elucidativo. Todorov também afirma que o policial clássico apresenta uma dualidade estrutural, ou seja, articula duas histórias, a história do crime e a história da investigação: “ a primeira história ignora totalmente o livro, isto é, ela nunca se confessa livresca (...) em compensação, a segunda história deve não só levar em conta a realidade do livro, mas ela é precisamente a história desse livro" (TODOROV, 1970, p. 97).

Partindo dessa definição inicial, o autor constata que, a rigor, a dualidade acima referida coincide com o que os formalistas russos, por sua vez, denominaram 'fábula' (o crime) e 'trama' (a maneira como o autor nos apresenta o crime, ou seja, a própria narrativa). Assim, o gênero policial caracteriza-se pelo fato de mostrar lado a lado os dois aspectos que definem toda e qualquer narrativa: aquilo que se quer contar e a maneira como se conta. Podemos dizer, portanto, que Todorov, ao propor esta dualidade, nos dá pistas que alcançam os motivos de interesse deste gênero por parte da crítica, dos intelectuais e dos escritores enquanto instrumento privilegiado de reflexão sobre os aspectos constitutivos do discurso narrativo em sentido amplo.

Como efeito das transformações sofridas durante a passagem do século $\mathrm{XX}$, tanto no plano estético-literário quanto fora dele, surge por volta dos anos vinte a outra grande vertente do gênero: o policial americano, também conhecido como romance negro. De acordo com Todorov, o elemento de maior diferenciação, se pensado em contraposição à vertente clássica, é dado pela perda da imunidade do detetive. Sem garantias nem segurança de qualquer ordem, o detetive torna-se um personagem que passa a correr riscos, 
pode ser corrupto e até mesmo morrer. Além disso, nesta nova manifestação do policial, temos a fusão das duas histórias apontadas por Todorov ao analisar o policial clássico. Em suma, contrariamente ao que ocorre nos relatos à la Poe ou à la Conan Doyle, a narração é coincidente à ação propriamente dita: "nenhum romance negro é apresentado sob a forma de memórias, não há ponto de chegada a partir do qual o narrador abranja os acontecimentos passados; não sabemos se ele chegará vivo ao final. A prospecção substitui a retrospecção" (Todorov, 1970, p.98-99).

Vale ressaltar que os detetives desta vertente são comumente chamados de hardboiled (linha-dura), pois são personagens que aliam o raciocínio indutivo-dedutivo a métodos mais práticos, como o uso da violência para conseguir pistas, além da utilização de medidas à margem da lei. Pode-se dizer que a violência é um aspecto predominante nesta vertente que se consolidou nos Estados Unidos, sobretudo depois da segunda grande guerra, e que foi divulgada na França através da publicação da série noir. Desta vez, o leitor não precisa esperar necessariamente pelas últimas páginas para saber quem é o culpado. Em muitos casos, assistimos à preparação de um crime e nossa curiosidade vai ser levada em direção ao desenrolar dos fatos: quem vai morrer; quem vai se salvar; quem será pego; a busca do detetive pelo(s) assassino(s) e as armadilhas e riscos enfrentados. Da mistura destes dois tipos apresentados por Todorov nasceu o chamado romance de suspense. Da vertente clássica, conserva a narrativa de detecção na qual a inteligência do detetive e sua busca pela captura do(s) criminoso(s) ganham páginas de destaque no corpo da narrativa. Já da vertente americana, mantém a incerteza do sucesso da investigação aliada à violência. Desta forma, o enfoque é dado à história que se desenrola no presente. Podemos observar que muitas das narrativas policiais contemporâneas se caracterizam justamente por aliarem traços compositivos do policial clássico e do americano.

\section{A ficção policial em Jorge Luis Borges}

Jorge Luis Borges é um dos nomes mais importantes da literatura argentina do século XX. Nasceu em 1899, em Bueno Aires, e morreu em 1986, em Genebra. Borges deixou uma extensa obra entre poesia, ensaio, resenha e conto. Nos anos quarenta, com a publicação do livro de contos Ficções, tem início a consagração que marcaria toda a sua carreira. Borges nunca escreveu um romance; postulava que a estrutura de um conto é suficiente para o desenvolvimento de uma narrativa. No entanto, foi leitor voraz de 
inúmeros romances, incluindo policiais. Chesterton, Poe, Connan Doyle são alguns dos autores de narrativas policiais lidos por ele.

Em julho de 1935, Borges publicou um artigo intitulado "Os labirintos policiais e Chesterton" no qual enumera algumas regras que devem gerir as narrativas policiais. Tais regras são enunciadas tomando como ponto de partida $O$ candor do Padre Brown, do escritor inglês Chesterton, livro exemplar, segundo Borges, no que diz respeito à produção deste gênero. A seguir temos os princípios estabelecidos no ensaio borgeano:

1) Limite discricionário de seis personagens;

2) Declaração de todos os elementos do problema;

3) Avara economia dos meios;

4) Primazia do como sobre o quem;

5) Pudor da morte;

6) Necessidade e maravilha na solução. (BORGES, 1982)

A atração do autor por esta modalidade narrativa não se expressou apenas através do referido artigo. Numerosos textos críticos publicados por Borges em jornais e revistas, bem como textos de ficção escritos individualmente ou em colaboração com Bioy Casares testemunham seu interesse pelo gênero policial. A título de exemplo, citamos o artigo " $\mathrm{O}$ conto policial" (BORGES, 1995), bem como as resenhas publicadas na revista argentina $E l$ Hogar no fim dos anos trinta. No interior desse corpus crítico e ficcional, destacamos o conto "A morte e a bússola", publicado em 1942, que analisamos a seguir.

A princípio poderíamos dizer que "A morte e a bússola" é um conto legível à luz das regras enumeradas anteriormente, muito embora ao longo da narrativa as características de cunho policial sejam permeadas por outros tópicos recorrentes do universo borgeano (os da cabala e do labirinto, por exemplo), presentes na trama que envolve o detetive Lonrot. Limitemo-nos por ora à primeira dimensão do relato, a estritamente policial.

No que se refere à primeira regra, o autor limita seus personagens principais a quatro nomes (o detetive Lonrot; o cabalista judeu Yarmolinsky; o comissário Treviranus e o assassino Scharlach) sujeitando-se ao preceito de economia estipulado. Por outro lado, Borges faz o criminoso figurar na narrativa desde o início, já que Scharlach é citado logo no primeiro parágrafo como aquele que jurara morte a Lonrot, apesar deste último, achando-se um Dupin (um detetive clássico) desconsiderar tal ameaça. Além disso, todos os elementos constitutivos da armadilha, ou seja, do labirinto construído em torno de Lonrot são apresentados ao leitor já nas primeiras linhas. O narrador ocupa-se de nos 
mostrar os fatos relativos à investigação que conduz a trama, tal como o estudo do detetive e do assassino acerca das obras do cabalista sobre o 'tetragrámaton' (as quatro letras misteriosas do nome de Deus), aspecto condizente com a segunda regra:

\begin{abstract}
Dos muitos problemas que exercitaram a temerária perspicácia de Lonrot, nenhum tão estranho - tão rigorosamente estranho, diremos - como a periódica série de fatos sangrentos que culminaram na quinta de Triste-leRoy, entre o interminável olor dos eucaliptos. É verdade que Enrik Lonrot não conseguiu impedir o último crime, mas é indispensável que o previu. Tampouco adivinhou a identidade do infausto assassino de Yarmolinsky, mas sim a secreta morfologia da perversa série e a participação de Red Scharlach, cujo apodo é Scharlach, o Dândi. Esse criminoso (como tantos) jurara por sua honra a morte de Lonrot, mas este nunca se deixou intimidar. Lonrot julgava-se um puro raciocinador, um Auguste Dupin, mas algo nele havia de aventureiro e de taful. (BORGES, 1989, p.34)
\end{abstract}

Acerca da quinta regra, que sugere uma apresentação pudorosa e higiênica do crime, não é preciso que nos estendamos muito, pois o conto poupa-nos de detalhes sanguinários, sórdidos ou muito violentos. Vejamos como as regras três, quatro e seis são aplicadas.

Ao enunciar a terceira regra (avara economia dos meios), Borges postula a possibilidade de uma personagem se apresentar como duas em uma narrativa policial, desde que isso seja construído de maneira engenhosa e verossímil. Em "A morte e a bússola”, ele lança mão desse recurso em duas oportunidades. Primeiro, Scharlach se disfarça de Griphius fingindo ser a terceira vítima; depois o detetive Lonrot (e com ele o leitor) descobre ser a verdadeira e última vítima, ao que voltaremos mais à frente. Quanto à regra quatro (primazia do como sobre o quem), é possível afirmar que a descoberta do como (isto é: descobrir a lógica do labirinto criado pelo assassino em torno do detetive) é privilegiada até o instante final, sendo reservada a surpresa do quem (a identidade do criminoso e da última vítima) para as derradeiras passagens do conto.

Tais descobertas conduzem-nos à regra seis (necessidade e maravilha na solução), pois nada surpreenderia tanto o leitor quanto descobrir que o próprio detetive é enganado e morto por Scharlach. Assim, não temos como negar que "A morte e a bússola" segue os princípios borgeanos, mas se trata de uma obediência sui generis, visto que ao aplicar esse conjunto de premissas, Borges estabelece um vai-e-vem entre sujeição e transgressão, respeito e ruptura com o gênero policial. Vejamos como esse duplo jogo é feito e quais os elementos que o envolvem. 
Como vimos na primeira parte deste artigo, segundo o padrão clássico, o detetive é invulnerável a qualquer perigo e infalível do ponto de vista intelectual. A ele cabe o poder de observar e raciocinar lógica e dedutivamente a fim de descobrir a trajetória do criminoso e a identidade do assassino. Entretanto, com o passar do tempo, os autores foram transformando o modelo clássico de Poe (no qual a peça mais importante não é o assassino, mas sim o método científico e lógico de detecção) a fim de incrementar o suspense de suas narrativas e agradar um público cada vez mais experiente, exigente e ávido de mistério. Como consequência, a literatura policial passou a ter criminosos quase ou tão inteligentes quanto os detetives.

Em “A morte e a bússola", o narrador apresenta Lonrot como um detetive clássico, pois ele se julga um Dupin ao desconsiderar as ameaças daquele que lhe jurara vingança, Scharlach. Ele acredita apenas em seu poder de raciocínio e dedução, então, ao encontrar Yarmolinsky morto, Lonrot se preocupa em observar, estudar os preceitos judaicos de seus livros e tentar encontrar ligações coerentes entre os fatos. Em um dado momento, o conto reforça deliberadamente o modelo do detetive como raciocinador puro e o confronta à inépcia da polícia oficial. Representada na figura de Teviranus, pois este insiste na casualidade e obviedade da explicação para a morte do rabino: "Nós sabemos que o Tetrarca da Galileia possui as maiores safiras do mundo. Para roubá-lo alguém entrou aqui por engano. Yarmolinsky se levantou e o ladrão foi obrigado a matá-lo” (BORGES, 1989, p. 35).

Já Lonrot prefere as hipóteses interessantes: "Eis um rabino morto. Eu prefiro uma explicação puramente rabínica e não os percalços de um imaginário ladrão" (BORGES, 1989, p. 35). Pouco depois, o jornalista do Ydishe Zaitung entrevista Lonrot e publica um artigo onde revela o método de investigação adotado. Segundo o jornalista, Lonrot "tinha se dedicado a estudar os nomes de Deus para dar com o nome do assassino" (BORGES, 1989, p. 36). A partir daí, quem passa a raciocinar de forma mais perspicaz é o assassino.

Com efeito, tendo conhecimento da direção escolhida por Lonrot para desvendar o enigma, e auxiliado por uma 'edição popular da história dos Hasidim' publicada na época, Scharlach passa a condicionar os passos do detetive, na medida em que ele raciocina o raciocínio deste. Vale lembrar que a função desse livro popular mencionado quase que ao acaso por Borges em seu conto policial "A morte e a bússola” foi claramente explicitada por Ricardo Piglia em seu artigo intitulado "Teses sobre o conto". 
No início de 'A morte e a bússola', um lojista resolve publicar um livro. Esse livro está ali porque é imprescindível na armação da história secreta. Como fazer com que um gangster como Red Scharlach fique a par das complexas tradições judias e seja capaz de armar a Lonrot uma cilada mística e filosófica? Borges lhe consegue esse livro para que se instrua. (PIGLIA, 1986, p. 10)

O jogo duplo criado por Borges está, portanto, no fato de ele anunciar um detetive clássico com todas as características próprias desse modelo (e a rigor é através do raciocínio lógico de Lonrot que a secreta morfologia dos crimes é descoberta), mas subverter simultaneamente tal regra criando, de um lado, um criminoso que vai 'além' de sua natureza clássica e de outro um detetive que fica 'aquém' do modelo.

Outra marca dessa desobediência às regras postuladas pelo próprio autor é dada pela aplicação da premissa número três em que se anuncia a possibilidade de uma personagem se apresentar como duas no decorrer da narrativa. De fato, Borges utiliza esse recurso quando faz de Griphius um disfarce de Scharlach. Mas também faz com que uma única personagem desempenhe dois papéis centrais incompatíveis, já que o detetive acaba sendo a vítima principal. Em outras palavras, Borges fusiona duas personagens de natureza antagônica no policial clássico (o detetive e a vítima) em uma mesma pessoa: Lonrot.

Finalmente, assinalamos que a trama construída por Borges é tão engenhosa que não foge à sua regra de número quatro: ele efetivamente privilegia o 'como', ou seja, da morfologia dos crimes e é justamente a descoberta do 'como' que conduz o detetive até o local onde ocorrerá o último assassinato. Por outro lado, essa suposta obediência da primazia do 'como' sobre o 'quem' faz com que a descoberta do 'quem' (a identidade do assassino e da vítima) seja tão ou mais interessante do que o 'como'. Assim, ao cumprir as regras de sua própria tipologia policial, Borges vai além, obedecendo a forma e transcendendo seu conteúdo.

\section{Do enigma policial ao cabalístico: uma metáfora da leitura}

Referimo-nos até agora aos elementos especificamente policiais do conto de Borges. Passemos à análise de um outro tema presente no conto "A morte e a bússola" enquanto componente central da trama que envolve o detetive Lonrot: a Cabala.

Em verdade, o interesse de Borges pela Cabala não se fez presente somente nesta narrativa (em que o tema aparece entrelaçado ao enredo policial), mas em outros contos e alguns ensaios específicos sobre o assunto. No artigo "Vindicação da Cabala", publicado em 1932, na Revista Hefel, Borges deixa claro qual sua postura em relação à Cabala: "Não 
tenho intenção de vindicar a doutrina, mas tão somente os procedimentos hermenêuticos ou criptográficos que conduzem a ela". (BORGES, 1985, p. 27).

De fato, o pressuposto da inspiração mecânica da Bíblia ou, mais especificamente, o princípio segundo o qual o autor das Sagradas Escrituras é o Espírito Santo, traz consequências às quais Borges se refere da seguinte forma:

Simples formação sintática ou não, o certo é que a terceira ofuscada pessoa da enredada trindade é autor reconhecido das Escrituras. Gibbon, no capítulo de sua obra que se ocupa do Islam, inclui um censo geral das publicações do Espírito Santo, calculadas com certa timidez em umas cento e poucas. Porém, o que nos interessa agora é o Gênese: substância da Cabala. Os Cabalistas, assim como hoje em dia muitos cristãos, acreditavam na divindade dessa história e em sua deliberada redação por uma inteligência infinita. As consequências desse postulado são numerosas. O distraído esvaziamento de um texto corrente (por exemplo, as menções efêmeras do jornalismo) tolera uma quantidade sensível casualidade. Comunicam um fato, postulando-o, como informar que o sempre irregular assalto de ontem ocorreu em tal rua, tal esquina a tais horas da manhã; receita não representável por ninguém e que se limita a indicar o lugar tal, onde fornecem informações. Em indicações dessa natureza a extensão e a acústica dos parágrafos são necessariamente casuais. $\mathrm{O}$ oposto ocorre nos versos, cuja lei corrente é a sujeição do sentido às necessidades (ou superstições) eufônicas. $\mathrm{O}$ casual nos versos não é o som, mas o que significam. Assim é no primeiro Tennyson, em Verlaine e no último Swinburne, dedicados todos eles tão somente à expressão dos estados gerais, mediante as ricas aventuras de sua prosódia. Consideramos um terceiro escritor - tipo intelectual. Este, seja no manejo de sua prosa (como Valéry e De Quincey), seja no manejo de seu verso, não eliminou certamente a casualidade, porém restringiu-a, recusando, na medida do possível, sua imprevisível aliança. Remotamente ele se aproxima do Senhor, para quem o sentido da casualidade não tem sentido nenhum. (BORGES, 1985, p. 28)

Atentemo-nos a dois aspectos da citação borgeana: a recorrente menção à literatura para explicar a Cabala (ou tratar-se-ia do contrário?); a análise da relação entre causalidade e casualidade tal como ela se apresenta em diferentes tipos de textos. Segundo Borges, há certa classe de 'escritos' (notícias de jornal, por exemplo) nos quais muitas palavras estão ali por acaso: algumas delas não foram escolhidas propositadamente pelo emissor e poderiam ser suprimidas sem prejuízo do sentido geral; outras poderiam ser substituídas por termos de significado semelhante. Já nas Sagradas Escrituras cada palavra é obra da intenção divina e, portanto, impossível de ser substituída. Cada traço encontra-se ali como símbolo de algo maior e mais misterioso que estaria no 'verso invisível' das palavras, segundo Borges. 
Um texto em que a casualidade é suprimida completamente e em que tudo (cada letra, palavra etc) é, ao contrário, causal, coloca-nos na posição de nos perguntar a cada passo: o que o autor quis dizer?; o que significa?; por que escolheu determinada palavra ou determinada letra? Consequentemente, é um texto que deve ser infinitamente interrogado, inquirido. Aos cabalistas cabe essa tarefa, cuja doutrina parte do princípio básico de que não há acaso na composição bíblica. Afinal, como poderia haver acaso em um texto cuja autoria é um ser supremo, "que sabe de todos os fatos deste abarrotado mundo, mas igualmente os fatos que teriam lugar se o mais efêmero deles mudasse... e também os fatos impossíveis?” (BORGES, 1985, p. 29).

Podemos dizer então que a Cabala (por se propor a desvendar os versos invisíveis das palavras sagradas) representa, no plano religioso e de maneira hiperbólica, operações análogas às implicadas no plano profano da criação e recepção literárias. Daí a referência ao escritor que Borges caracteriza como intelectual, ou seja, aquele que não elimina a casualidade, porém a restringe. Para Borges, este terceiro tipo de escritor é autor de uma mensagem ou texto cujos sentidos um intérprete tem que desvendar: o leitor. Assim, a relação do cabalista com a Bíblia é análoga à do leitor com o texto literário: ambos vão ler e interpretar símbolos (palavras, sons, traços) a fim de desvendar o desconhecido presente nos textos.

Jorge Luis Borges volta ainda a se debruçar sobre o tema da cabala em ensaio inicialmente proferido como palestra e publicado posteriormente em livro sob o título Sete Noites (sendo cada uma das noites dedicada a um determinado tema). Nesse texto, o autor reafirma seu interesse pela doutrina como metáfora do pensamento:

Deus criou o mundo através das palavras, que foram o instrumento de sua obra (no dizer do grande escritor Saavedra Fajardo). Então Deus disse: que a luz seja. E a luz se foi. Daí se conclui que o mundo foi criado pela palavra $l u z$, ou pela entonação com que Deus disse a palavra luz. Se Deus tivesse dito outra palavra e com outra entonação, não teria sido criada a luz, mas outra coisa. Aqui chegamos a algo que é tão incrível quanto o que se disse até agora. Trata-se de algo sem dúvida chocante para nossa mentalidade ocidental - inclusive a minha. Mesmo assim, devo continuar. Quando pensamos nas palavras, pensamos de um ponto de vista histórico, já que as palavras foram inicialmente um som e só depois se formaram as letras. Na cabala (que quer dizer recepção, tradição) ocorre o contrário: supõe-se que as letras vieram primeiro; foram elas os instrumentos de Deus, e não os termos que elas significavam. É como se, contra toda a experiência, a escrita fosse anterior à pronúncia das palavras. Nesse sentido, nada é casual na Escritura, tudo nela tem que ser determinado por exemplo, o número de letras de cada versículo. Inventam-se depois equivalências entre as letras: a Escritura passa a ser tratada como uma escrita cifrada, criptográfica, e se inventam diversas leis para lê-la. Pode- 
se tomar, para cada letra da Escritura, outra palavra significada. Faz-se assim com cada uma das letras do texto. Pode-se também formar dois alfabetos, com as letras hebraicas. Um de $a$ a $l$, por exemplo, e outro de $m$ a $z$; as letras de cima são consideradas equivalentes às de baixo. Depois, pode-se ler o texto boustróphedron (para usar a palavra grega); ou seja, da direita para a esquerda, da esquerda para a direita e novamente da direita para a esquerda. Também se costuma atribuir um valor numérico às letras. Tudo isso forma uma criptografia a ser decifrada como resultados plausíveis - pois estes já foram previstos pela inteligência de Deus, que é infinita. Assim, através desse trabalho criptográfico que o lembra o Escaravelho de ouro, de Poe, chega-se à doutrina. (BORGES, 1987, p. 33).

Apesar de longa citação, a fala de Borges lança luz sobre a motivação do autor em eleger o tema da cabala para compor a trama de "A morte e a bússola" por ser uma doutrina que funciona - no campo da ficção - como metáfora (ou quem sabe uma hipérbole) da atividade de leitura/interpretação, atividade essencial ao homem, ao pensamento e, na lógica do gênero policial, à ação do detetive que realiza operações análogas aos cabalistas. Estes últimos se detêm à leitura da Sagrada Escritura em busca da verdade suprema acerca da criação do universo, do nome infalível de Deus (Tetragrámaton) e suas implicações, utilizando para tanto métodos específicos (leitura vertical, leitura em boustróphedon - da direita para a esquerda, uma linha; da esquerda para a direita, a linha seguinte; substituição de umas letras do alfabeto por outras; soma do valor numérico das letras). Também o detetive, usando um método particular (raciocínio lógico-dedutivo aliado à perspicácia), vai ler os indícios deixados pelo criminoso e depois interpretá-los a fim de chegar ao assassino.

Partindo, portanto, dessa problemática entre leitura e interpretação a partir do duplo jogo entre casualidade/causalidade e visível/invisível, enquanto polos organizadores da trama de "A morte e a bússola", podemos dizer que o que o detetive Lonrot faz no decorrer da narrativa é ler e interpretar os indícios cabalísticos manipulados por aquele que lê e interpreta seu percurso de leitura: Scharlach, o criminoso. Vejamos.

O primeiro crime ocorrido é fruto do acaso, pois Yarmolinsky, cabalista judeu, é morto por engano. Daniel Azevedo, bandido da gangue de Scharlach, é enviado por este para, junto a outros comparsas, roubar as safiras do tetrarca da Galileia, hospedado no quarto em frente ao do cabalista. Azevedo trai o grupo e em uma data anterior à combinada dirige-se sozinho ao hotel para se apoderar das pedras preciosas, mas acaba invadindo por engano o quarto de Yamorlinsky e o mata para não ser pego. Após esse episódio inicial, 
temos um diálogo no qual Treviranus aventa a hipótese de um erro, do acaso, mas Lonrot rejeita completamente essa possibilidade:

\begin{abstract}
Não há que procurar três pés ao gato - dizia Treviranus, brandindo um imperioso charuto. Todos sabemos que o tetrarca da Galileia possui as maiores safiras do mundo. Alguém para roubá-las teria penetrado aqui por equívoco. Yarmolinsky levantou-se; o ladrão teve que matá-lo. Que lhe parece?

- É possível, mas não interessante - respondeu Lonrot. - O senhor replicará que a realidade não tem a mínima obrigação de ser interessante. Eu lhe responderei que a realidade pode prescindir dessa obrigação, porém não as hipóteses. Naquela que o senhor improvisou, intervém copiosamente o acaso. Eis aqui um rabino morto; preferiria uma explicação puramente rabínica, não os imaginários percalços de um imaginário ladrão. (BORGES, 1989, p. 33).
\end{abstract}

Defrontamo-nos nesta passagem com duas concepções diferentes de leitura e escrita do mundo. A primeira refere-se à figura de Treviranus: aquele que lança mão da casualidade. A segunda diz respeito à figura de Lonrot: o tipo de leitor que não elimina completamente a casualidade, mas a restringe.

Após o diálogo, seguem-se três acontecimentos a princípio desvinculados entre si. Ficamos sabendo, via narrador, juntamente com Lonrot e Treviranus, que no momento em que Daniel Azevedo entra no quarto, Yarmolinsky acabava de datilografar a seguinte sentença: "A primeira letra do nome foi articulada". A suposta coincidência entre este fato e a condição da vítima deflagará a leitura puramente cabalística de Lonrot. Além disso, após dez dias de ocorrido o crime, um jornalista judeu entrevista Lonrot e, diante da visível curiosidade do detetive pela cabala, publica uma reportagem que este estava a estudar os nomes de Deus para chegar ao nome do assassino. Por fim, aproveitando a popularidade do caso, um livreiro interessado apenas no sensacionalismo do mercado editorial, publica uma edição popular da História da seita dos Hasidim.

Temos, portanto, um crime cometido por engano exatamente no momento em que a vítima está escrevendo uma sentença 'qualquer', a conjectura exagerada de um jornalista e a publicidade do caso aliados ao oportunismo de um livreiro. No entanto, aquilo que $a$ priori é uma sucessão de equívocos ou acontecimentos mais ou menos fortuitos, ganha novo sentido, uma outra coerência para o futuro criminoso Scharlach. Ao saber do raciocínio do detetive (sua leitura do caso) e tendo a possibilidade de se instruir sobre a cabala e sobre os temas lidos pelo raciocinador, Scharlach passa a manipular os acontecimentos para que Lonrot continue lendo e interpretando os fatos na direção por ele 
escolhida; Scharlach passa a "justificar" a leitura de Lonrot tanto que no desfecho, diante da surpresa e incompreensão do detetive, Scharlach afirma: "Compreendi que você conjeturava que os Hasidim tinham sacrificado o rabino; dediquei-me a justificar essa conjetura." (BORGES, 1989, p.39). É graças, portanto, a uma constelação de casualidades que Scharlach descobre os instrumentos necessários para tramar o texto/labirinto em torno do detetive e concretizar sua vingança.

A segunda morte do conto é ordenada por ele e tem como vítima Daniel Azevedo. Ele é apunhalado no peito, assim como Yarmolinsky, a três de janeiro (um mês exato após a morte do rabino) em um lugar exatamente a oeste do local do primeiro crime, uma tinturaria, onde é deixada a seguinte inscrição: "A segunda letra do nome foi articulada" (BORGES, 1989, p.37). São acontecimentos que entram simultaneamente em dois sistemas de significação: de um lado há uma vingança (para Scharlach) e, de outro, uma mensagem que reforça a hipótese de leitura de Lonrot.

O terceiro crime é na verdade uma simulação. Scharlach se transveste de Griphius, hospeda-se em uma taverna e confabula com seus bandidos para ser sequestrado no dia três de fevereiro. Lonrot é chamado ao local (que fica exatamente a leste da tinturaria onde se deu a segunda morte) e encontra a inscrição de que "a terceira letra do Nome foi articulada". Ao investigar o aposento onde supostamente dormira Griphius, Lonrot descobre indícios que ele relaciona com os crimes anteriores: um exemplar de um livro em latim (o Philologus hebraegraecus), uma estrela de sangue pintada no chão, a afirmação das testemunhas sobre a língua usada por Griphius, o ídiche. Todos esses pequenos detalhes são cuidadosamente preparados por Scharlach que prevê a leitura que fará Lonrot.

A última peça do jogo é então lançada: Scharlach envia uma carta e um mapa ao comissário Treviranus, aquele que aventa a hipótese de casualidade o tempo todo, que envia o material a Lonrot. O mapa aponta a equidistância entre os locais dos crimes, o que forma uma simetria no espaço compondo um triângulo equilátero perfeito. A carta faz explícita referência à simetria no tempo, visto que os crimes ocorreram no dia três de cada mês (dezembro, janeiro e fevereiro) e afirma que não haveria um quarto crime. Mas Lonrot, com a ajuda de uma bússola e apoiado em seus estudos acerca do Tetragrámatron desvenda o que estaria oculto nessa suposta ausência de um quarto crime, supondo que haveria de fato uma quarta morte, em um lugar ao sul, no dia quatro de março, pois a figura geométrica correta desenhada simbolicamente pelo assassino seria a de um losango, uma vez que "o dia hebreu começa ao anoitecer e dura até o anoitecer seguinte" (Borges, 
1989, p. 38). Em outros termos, os assassinatos ocorreram no dia quatro de cada mês e não no terceiro. Lonrot apenas não raciocinou que ele seria a quarta e última vítima, sendo uma vítima dupla: de seu raciocínio lógico-dedutivo equivocado suplantado pela inteligência de seu assassino.

\section{Considerações Finais}

Após as considerações feitas ao longo deste texto, podemos afirmar que os elementos presentes em "A morte e a bússola" articulam dois níveis de significação, uma dupla leitura (talvez até tripla): a visível, ou seja, aquela que seria verossímil para todos os leitores não iniciados no universo das relações cabalísticas (representados pelo personagem Treviranus) e a invisível: aquela que estaria cifrada no visível aparente e destinada apenas a Lonrot, o detetive. Ocorre, porém, que a mensagem invisível decifrada por Lonrot (e cifrada por Scharlach) esconde, por sua vez, uma significação oculta até o derradeiro instante do conto. Por trás dos jogos cabalísticos, da série quaternária descoberta no mapa e simbolizada por losangos, esconde-se a motivação original da trama, sua causa primeira: o ódio de Scharlach e seu desejo de vingança, compondo assim um terceiro nível de significação.

Assim, a leitura de Lonrot teria sido perfeita ou completa se, junto ou paralelamente ao raciocínio lógico-dedutivo (aquele que procura estabelecer ligações estritamente causais e coerentes entre os fatos), Lonrot tivesse sido capaz de aventar a hipótese de casualidade, ou seja, uma causalidade outra, completamente diversa daquela por ele aventada.

O conto policial "A morte e a bússola" leva para o campo ficcional questões que são próprias da atividade humana de leitura e interpretação dos fatos do mundo, subvertendo as prerrogativas do gênero e indo além. A narrativa de Borges apresenta dois tipos de leitores que se enfrentam e confrontam no texto. Lonrot é aquele que suprime completamente a casualidade, o que lhe custa a vida. Já Scharlach é aquele que não só é capaz de fazer bom uso do acaso, como de transformá-lo em causalidade. E é graças a tais versatilidade e inteligência que essa personagem ultrapassa a perspicácia do detetive, na medida em que seu campo de raciocínio e de variáveis é muito mais amplo. Scharlach "não só é leitor dos textos cabalísticos, mas autor e leitor da leitura desses textos que ele prevê para Lonrot”. (MOLLOY, 1979, p. 27).

Sendo assim, a narrativa policial de Borges coloca em evidência algumas das características desse gênero, conforme apresentadas por Todorov, porém as subverte. Lonrot tem uma matriz clássica (julga-se infalível e aposta incondicionalmente em seu 
raciocínio lógico-dedutivo), mas o desfecho de "A morte e a bússola" surpreende ao nos apresentar um criminoso muito mais astuto que o detetive, transformado na última vítima de uma trama que tem início casualmente, mas que se desenvolve duplamente por meio da perspicaz escrita do assassino e equivocada leitura do detetive. Essa duplicidade nos remete de volta à citação de Boileau; Narcejac (1991): "a raiz profunda e, por assim dizer, metafísica do romance policial está aí: somos seres empenhados em extrair, de qualquer jeito, o inteligível do sensível”. A atividade humana de conferir significado àquilo que é da ordem experiencial tem no campo ficcional borgeano espaço privilegiado enquanto metáfora da própria criação literária que, inevitavelmente, envolve dois eixos: aquele que escreve e constrói um universo de significados e aquele que, ao ler, procura desvendá-los.

\section{Referências}

BOILEAU; NARCEJAC. O romance policial. São Paulo: Editora Ática, 1991.

BORGES, J. L. A Cabala. In: Sete noites. São Paulo: Editora Max Limonad, 1987. A morte e a bússola. In: Ficções. São Paulo: Editora Globo, 1989.

Os labirintos policias e Chesterton. In: MONEGAL, R.E. Borges por Borges. Porto Alegre: LPM Editores, 1982. . Uma vindicação da Cabala. In: Dicussão. São Paulo: Hefel, 1985.

MOLLOY, S. Rúbricas Textuales. In: Las letras de Borges. Buenos Aires: Sudamericana, 1979.

PIGLIA, R. Formas breves. Buenos Aires: Editorial Anagrama, 1986.

TODOROV, T. Tipologia do romance policial. In: As estruturas narrativas. São Paulo: Perspectiva, 1970. 